\title{
OS DESAFIOS DAS PRÁTICAS CURRICULARES EM CONTEXTOS DIVERSIFICADOS: o caso dos refugiados sírios nas escolas brasileiras
}

\author{
Vinícius Alves da Silva? \\ Poliana Fabíula Cardozo²
}

\section{RESUMO}

O artigo que aqui se apresenta trata da questão da falta de políticas públicas para receber as diferenças culturais e de idioma vinculadas à inclusão de refugiados sírios no contexto educacional. Tem como objetivo investigar e debater como são acolhidos na esfera educacional mediante as leis educacionais e as políticas públicas inerentes às dificuldades idiomáticas e diferenças culturais. A análise teórica se fundamenta na pesquisa bibliográfica que explanou as compreensões atreladas à inclusão e diversidade cultural. A análise documental pesquisou a Lei de Diretrizes e Bases da Educação, os Parâmetros Curriculares Nacionais e a Proposta Curricular de Santa Catarina. O eixo final de análise foi executado através de pesquisa de campo, com entrevistas em escolas da rede estadual de ensino na cidade de Florianópolis. Os resultados apontam que, embora as leis garantam o respeito à diversidade e prezam pela inclusão no ambiente escolar, não especificam a questão do aluno refugiado, não oferecendo nenhum tipo de apoio ao acolhimento deste, como aprendizagem da língua portuguesa ou acompanhamento psicológico, tendendo muito mais a excluir do que incluir e que há falhas na implementação de políticas públicas e até mesmo, a falta destas.

Palavras-chave: Políticas Públicas. Diferenças Culturais. Inclusão.

\footnotetext{
1 Bacharel e Licenciado em História, Especialista em Ciências da Religião, Mestrando em Educação pela Universidade Estadual do Centro-Oeste do Paraná - UNICENTRO. Orcid iD: https://orcid.org/0000-0002-7707-2032. E-mail: vinicius_alvesdasilva@hotmail.com

2 Bacharel e Mestre em Turismo, Doutora em Geografia, Professora do Programa de PósGraduação - Mestrado em Educação - Universidade Estadual do Centro-Oeste do Paraná UNICENTRO. Orcid iD: https://orcid.org/0000-0001-5876-1302 E-mail: polianacardozo@yahoo.com.br
} 
THE CHALLENGES OF CURRICULAR PRACTICES IN DIVERSE CONTEXTS: THE CASE

\author{
OF SYRIAN REFUGEES IN BRAZILIAN SCHOOLS
}

\begin{abstract}
The article here presented deals with the issue of the lack of public policies to receive cultural differences and language linked to Syrian refugee inclusion in the educational context. Aims to investigate and debate as they are welcomed in the educational sphere through the educational laws and public policies involved difficulties idiomatic and cultural differences. The theoretical analysis is based on literature search that explained the understandings linked inclusion and cultural diversity. The documentary analysis has researched the law of Guidelines and Bases of education, the National curricular parameters and the Curricular Proposal. The final axis of analysis was run through field research, with interviews in schools in the State schools in the city of Florianópolis. The results show that although the laws guaranteeing the respect for diversity and value for the inclusion in the school environment, do not specify the issue of student refugee, not offering any kind of support to this host, such as learning the language Portuguesa or psychological, tending more to exclude than include and that there are flaws in the implementation of public policies and even the lack of these.
\end{abstract}

Keywords: Public Policy. Cultural Diferences. Inclusion.

\title{
LOS DESAFÍOS DE LAS PRÁCTICAS CURRICULARES EN DIVERSOS CONTEXTOS: EL CASO DE LOS REFUGIADOS DE SIRIA EN LAS ESCUELAS BRASILEÑAS
}

\section{RESUMEN}

El artículo que aquí se presenta aborda la cuestión de la falta de políticas públicas para recibir lengua y diferencias culturales ligadas a la inserción de refugiados sirios en el contexto educativo.Pretende investigar y debatir como son recibidos en el ámbito educativo a través de las leyes educativas y las políticas públicas implicadas las diferencias idiomáticas y culturales dificultades. El análisis teórico se basa en la búsqueda de literatura que explica los entendimientos vinculados al inclusión y la diversidad cultural. El análisis documental ha investigado sobre la ley de directrices y Bases de la educación, los parámetros curriculares nacionales y la propuesta Curricular. El último eje de análisis se ejecutó a través de la investigación de campo, com entrevistas em las escuelas del estado em la ciudad de Florianópolis. Los resultados muestran que aunque las leyes que garanticen el respeto a la diversidade y el valor de la incluión em el ambiente escolar, no se especifica el número de refugiados de estudiante, que no oferece ningún tipo de apoyo a este host, como aprendizaje de la lengua Portuguesa o más psicológica, tendientes a excluir que incluir y allí son deficiências em la implementación de políticas públicas y aún la falta de estos.

Palabras clave: Políticas Públicas. Diferencias Culturales. Inclusión. 


\section{INTRODUÇÃO}

O panorama migratório no Brasil sempre esteve em evidência em produções científicas, sendo objeto de análise de pesquisadores. Isso se intensifica em virtude do grande contingente de refugiados que foram obrigados a deixar seus países em razão de fatores que os impedem de ter acesso aos seus direitos, liberdade, segurança e bem-estar. A partir disto, denota-se a existência de desafios que não se limitam somente em recebêlos, mas em acolhê-los e integrá-los, demonstrando a necessidade de uma contextualização da temática do refúgio com a educação. Desvela-se também, a iminente necessidade de criação e implementação de políticas públicas que visem à inclusão do refugiado no ambiente escolar.

Acolher pressupõe dinâmicas que representam o recebimento e a inserção do migrante, incluindo assistência imediata. A integração constitui um processo complexo que abrange múltiplos fatores, como socioeconômicos, culturais, políticos e a construção de relações sociais com os membros da comunidade local. É o processo pelo qual os refugiados se tornam progressivamente parte da sociedade que os recebe (MOREIRA, J. B., 2014).

Isto posto, o artigo que aqui se apresenta está ancorado em uma abordagem da cultura (EAGLETON, 2005; BHABHA, 1998; HALL, 2006), da diversidade cultural na escola, sob uma perspectiva intercultural para $O$ acolhimento às diferenças (SODRÉ, 2006; CANDAU, 2008). Considera as implicações entre o currículo e a cultura, recorrendo-se à Moreira (2009) e trata ainda, da temática da inclusão perante as diferenças (SANTOS, 2003). A partir deste arcabouço bibliográfico, o estudo segue para a pesquisa documental sobre as leis e as políticas públicas educacionais voltadas aos alunos refugiados.

Tem assim, como objetivo investigar e debater a maneira como os refugiados sírios são acolhidos na esfera educacional mediante as leis educacionais e analisa a questão das políticas públicas e das práticas educacionais voltadas ao acolhimento das diferenças e a inclusão e integração do aluno refugiado no processo de ensino. Justifica-se pela 
importância da discussão acerca de ações inclusivas e aprimoramento de políticas públicas e práticas educacionais que garantam a igualdade de direitos e o respeito às diferenças.

Para o alcance do objetivo proposto, valeu-se de uma pesquisa com abordagem qualitativa englobando etapas metodológicas de pesquisa bibliográfica e documental, bem como entrevistas. Ao adotar uma perspectiva qualitativa, o pesquisador se preocupa em entender as percepções que os indivíduos têm do mundo. Este tipo de pesquisa qualitativa trabalha com o universo dos significados, motivos, aspirações, crenças, valores e atitudes, desvendando os fenômenos, levando em conta a sua complexidade e particularidade (LANKSHEAR; KNOBEL, 2008).

A análise teórica se fundamenta na pesquisa bibliográfica que explanou as compreensões conceituais atreladas à questão da inclusão do refugiado no contexto escolar e aos enfoques sobre as relações entre identidades, diversidade cultural e currículo escolar. A análise documental pesquisou acerca dos ordenamentos jurídicos no campo da educação, com enfoque na Lei de Diretrizes e Bases da Educação, nos Parâmetros Curriculares Nacionais e na Proposta Curricular de Santa Catarina. O eixo final de análise foi executado através de pesquisa de campo, com entrevistas em duas escolas da rede estadual de ensino na cidade de Florianópolis, observando a relação entre alunos refugiados sírios e a comunidade escolar e as dinâmicas educacionais para promoção da integração.

Pretende-se a partir deste estudo, trazer contribuições para a implementação de políticas públicas, além de alavancar a criação de projetos no sentido do acolhimento, do respeito à diversidade cultural, da inclusão e integração escolar de alunos em situação de refúgio.

\section{A abordagem da diversidade cultural na escola: o acolhimento às diferenças}

As sociedades multiculturais apresentam uma intensidade crescente a partir das migrações e deslocamentos dos povos produzindo sociedades 
étnica ou culturalmente múltiplas (HALL, 2003). A partir da emergência das migrações, da diversidade cultural e da globalização, a escola está sendo chamada a trabalhar com a pluralidade de culturas e a reconhecer os diferentes sujeitos socioculturais presentes em seu contexto, abrindo espaços para a manifestação e valorização das diferenças, em vez de preservar uma tradição monocultural (MOREIRA; CANDAU, 2003). Não obstante, para Hall (2003), continua-se praticando o "multiculturalismo de boutique", em que celebram-se os turbantes africanos, os colares de sementes indígenas, a comida japonesa, mas o ensino continua baseado na cultura hegemônica.

A abordagem da diversidade cultural na escola se realiza a partir do encontro de valores culturais e do entendimento dessa diversidade cultural como princípio educativo:

[...] uma ação docente [...] que enfrente os desafios provocados pela diversidade cultural na sociedade e nas salas de aulas, requer uma postura que supere o "daltonismo cultural" usualmente presente nas escolas, responsável pela desconsideração do "arco-íris de culturas" com que se precisa trabalhar. Requer uma perspectiva que valorize e leve em conta a riqueza decorrente da existência de diferentes culturas no espaço escolar (MOREIRA; CANDAU, 2003, p. 161, grifos do autor).

Em meio ao contexto migratório, Hall (2003, p. 45), refere que as migrações "estão mudando de composição, diversificando as culturas e pluralizando as identidades culturais [...]". O imiscuir de diversas culturas se estampa na situação das pessoas que, habitando em outro local que não a sua terra natal, são pressionadas a se redefinir, a se modificar ou a se adaptar ao novo meio cultural. Os migrantes aderem a novos costumes, além dos aspectos de sua cultura de origem e suas tradições, e, ao unir aspectos de duas ou mais culturas, acabam formando as culturas híbridas.

Estes processos de hibridização cultural são mobilizadores da construção de identidades, sendo vistos como elemento importante na dinâmica dos diferentes grupos socioculturais (CANDAU, 2008). Para Eagleton (2005, p. 28), "todas as culturas estão envolvidas umas com as outras; nenhuma é isolada e pura, todas são híbridas, heterogêneas, extraordinariamente diferenciadas e não monolíticas". 
Neste aspecto, Candau (2008, p. 22) defende a perspectiva intercultural, na qual as culturas estão em processo contínuo de elaboração, construção e reconstrução e, mesmo tendo suas raízes históricas e dinâmicas, "não fixam as pessoas em determinado padrão cultural engessado". Esta perspectiva visa promover uma educação para o diálogo entre diferentes grupos sociais e culturais, que reconheça o outro, que enfrente os conflitos provocados pela assimetria entre os diferentes grupos socioculturais e que favoreça a inclusão das diferenças.

O processo educativo deve se pautar na interculturalidade que implica o reconhecimento da existência de múltiplas culturas, cada uma caracterizada por suas especificidades e particularidades, superando toda forma de hegemonização de uma sobre as outras, havendo troca de sentidos e valores que possam enriquecer todas.

Trata-se de um reconhecimento recíproco, tecido mediante um diálogo que implica renúncias e afirmações de todas as partes envolvidas. A interculturalidade não se coloca apenas no plano simbólico, superestrutural. Ela pressupõe uma hospitalidade concreta dos diferentes. A dificuldade de se aceitar o diferente e a sua diferença, de integrá-lo efetivamente. Não basta a tolerância (SEVERINO, 2016, p. 215).

O Brasil apresenta uma configuração de diversidade cultural, sendo construído com base em relações entre as diferentes culturas e etnias e isso têm sido uma constante através da história. Nesse pressuposto, as questões culturais não podem ser ignoradas pelos professores para que a escola não corra o risco de se distanciar dos universos simbólicos, das mentalidades e das inquietudes dos alunos (CANDAU, 2008).

A diversidade cultural deve ser utilizada dentro do contexto escolar como um todo, seja na aprendizagem de conteúdo, ou na aprendizagem social e de cidadania, sendo necessário, no processo educativo, possibilitar a troca de conhecimentos no âmbito cultural, propiciando um ambiente que dissemine o respeito mútuo e favoreça a aprendizagem em relação à descoberta e exploração de novas culturas. O processo de integração em meio a novas representações culturais não desconstrói aspectos culturais 
construídos anteriormente, mas denotam que a associação a estas representações agregam e se fazem necessárias para favorecer o sentimento de pertencimento e identificação ao novo ambiente.

Isso ficou claro em uma das falas de uma aluna síria, ao ser perguntada sobre as diferenças culturais vivenciadas. Citando o ato de cumprimentar outra pessoa, o pesquisador pergunta se na Síria, a forma de cumprimentar os amigos é igual no Brasil e a resposta foi a seguinte: "Não! Na Síria as meninas não podem dar a mão e nem beijos. Apenas dizemos oi". O pesquisador pergunta ainda se caso alguém estender a mão para cumprimentar, o que ela faria e após alguns segundos em silêncio, a aluna responde: "Estou começando a dar a mão. Moro no Brasil e preciso saber conviver com as pessoas. Aqui dar a mão não é errado".

Neste sentido, pode-se citar o fenômeno de tradução cultural, definida por Hall (2006), como o processo de negociação vivenciado por migrantes, entre matrizes culturais, novas e antigas. O migrante tem diante de si, uma cultura que não o assimila e, ao mesmo tempo, não perde completamente sua identidade originária, porém é necessário o diálogo constante com as duas realidades. Para Bhabha (1998, p. 292), a tradução cultural se mostra como a forma pela qual "o novo entra no mundo". E utiliza uma metáfora para descrever o conceito de tradução cultural, na qual estão reservados três espaços para diferentes aspectos da transferência intercultural. 0 primeiro espaço sendo do colonizador, o segundo, do colonizado e o terceiro espaço reservado para a interação e comunicação entre culturas. Um espaço "onde a negociação das diferenças incomensuráveis cria uma tensão peculiar às existências fronteiriças" (BHABHA, 1998, p. 300).

A cultura como estratégia de sobrevivência é tanto transnacional como tradutória [...] A cultura é tradutória porque essas histórias espaciais de deslocamento - agora acompanhadas pelas ambições territoriais das tecnologias 'globais' da mídia - tornam a questão de como a cultura significa, ou o que é significado por cultura, um assunto bastante complexo. [...] A dimensão transnacional da transformação cultural - migração, diáspora, deslocamento, relocação - torna o processo de tradução cultural uma forma complexa de significação. O discurso natural(izado), unificador, da "nação", dos "povos" ou da tradição "popular" autêntica, não pode 
ter referências imediatas. A grande, embora desestabilizadora, vantagem dessa posição é que ela torna progressivamente conscientes da construção da cultura e da invenção da tradição (BHABHA, 1998, p. 241, grifos do autor).

Este encontro de valores culturais que se apresenta neste processo de integração entre alunos brasileiros e estrangeiros deve partir do entendimento da diversidade cultural como algo enriquecedor, instigando a aprendizagem de outros e novos valores sociais e culturais. A possibilidade de troca de conhecimentos no âmbito cultural propicia um ambiente de respeito e inclusão.

Acerca de contextos de diferença, Sodré (2006, p. 74), defende que "a percepção da diversidade vai além do simples registro da variedade das aparências, porque o olhar, ao mesmo tempo em que percebe, atribui um valor e, claro, determinada orientação de conduta". O autor explica esta afirmação com o exemplo de um policial ao pedir documentos a uma pessoa na rua. O que o leva a fazer isso é a atribuição de valor, ou seja, pede os documentos àquela pessoa pelo grau de valor social que é dado àquele tipo de aparência.

Quanto à diferenciação, Sodré (2006, p. 8), afirma que se pensa a diferença como um ponto de partida e se julga "a partir da identidade da diferença do outro". Assim exemplifica:

Você vê alguém com um turbante na cabeça e pensa que já sabe tudo sobre ele, que é, por exemplo, árabe, logo, islamita, logo investido de determinada disposição frente ao mundo. O racismo apresenta-se geralmente como esse "saber automático" sobre o Outro. Os preconceitos funcionam assim na prática: valem para qualquer outra forma diversa (SODRÉ, 2006, p. 8).

Sodré (2006, p. 11), afirma que os indivíduos são seres singulares que "coexistem em sua diversidade", não são iguais, nem desiguais e refere que o fato de se dizer que alguém é igual ou diferente de outro ocorre devido às comparações que se faz. "Comparamos como se fosse o caso de identificar objetos. E comparamos para exercer poder, para dominar" (SODRÉ, 2006, p. 11). 
Depreende-se que os alunos migrantes não abandonam a sua cultura e o entendimento de suas diferenças culturais pode colaborar com o processo de adaptação no contexto escolar.

[...] O culturalismo contemporâneo preocupa-se bastante com o múltiplo dos costumes, das crenças, etc., mas de uma maneira apenas intelectualista, ora com o objetivo político de obter uma tolerância entre as comunidades culturais ou religiosas, ora com intenções puramente turísticas, sem chegar ao núcleo do problema, que é a verdadeira compreensão (aproximação e aceitação) do diferente concreto (SODRÉ, 2006, p 7).

A valorização da cultura é defendida visando o desenvolvimento de práticas pedagógicas voltadas ao conhecimento dos elementos culturais dos alunos, auxiliando no desenvolvimento dessas iniciativas e estratégias educativas. Valorizar o conhecimento sobre a cultura brasileira e síria significa, portanto, uma tomada de consciência sobre a existência de outros referenciais que constituem os saberes e valores sociais e culturais da sociedade.

Barzotto (2004, p. 93), traz para o debate o uso de três verbos: respeitar, valorizar e adequar. Segundo ele, "estes verbos são usados para propor atitudes consideradas corretas a serem adotadas frente às variedades praticadas pelos alunos do ensino fundamental e médio". Inicia a discussão pelo verbo respeitar, quando se afirma que o professor deve respeitar a variedade do aluno. Defende que "a insistência em reafirmar o dever de respeitar, mais parece uma aceitação pacífica da existência de desrespeito do que uma resistência ativa" (BARZOTTO, 2004, p. 94). Para ele:

Geralmente as propostas de ensino calcadas na vertente que se sustenta no verbo respeitar, não fazem mais do que isso, suportar, aturar ou tolerar, já que atualmente tornou-se imperativa a idéia de tolerância (BARZOTTO, 2004, p. 94).

Continuando esta discussão, outro verbo bastante usado é valorizar, que também pressupõe hierarquia e "manifesta a exigência de uma postura que permita ao seu usuário o reconhecimento de que algo tem pouco ou nenhum valor" (BARZOTTO, 2004, p. 94). 
Barzotto (2004, p. 95), cita que as propostas e o trabalho pedagógico centrados no verbo adequar podem ser discriminatórios, pois "faz o movimento de partir da variedade de menor prestígio em direção à de maior prestígio. É aquele que é julgado inadequado que vai ser convocado a adequar-se".

A partir disto, Barzotto (2004, p. 95), defende uma proposta de trabalho pedagógico calcada no verbo incorporar, sendo que a partir deste se propiciaria "Um espaço de trabalho com as variedades praticadas pelos alunos, de modo que se pudesse explorar sua produtividade na comunicação diária, na consideração das identidades dos grupos sociais".

Sendo assim, as políticas públicas e as dinâmicas propostas para o favorecimento e a efetivação da inclusão de alunos estrangeiros deveriam se basear na incorporação de novas culturas, novas características: nem respeitar, nem valorizar, nem adequar. Conforme defendido por Barzotto (2004, p. 96):

Admitindo-se ou recebendo-se as variedades na sala de aula, sem hierarquização ou valoração, respeita-se melhor a Constituição, pois evitam-se os danos causados por julgamentos negativos como o de atribuição de uma falta de valor ou de inadequação.

A abordagem da diversidade linguística e cultural vincula-se a uma perspectiva complexa que segue em direção à criação e recriação das práticas pedagógicas que se dão com base na relação educativa instituída entre os alunos e outros no processo de aprendizagem. A articulação entre igualdade e diferença é trabalho árduo a ser assumido pela educação escolar. Nesse sentido, para Candau (2008, p.49), a questão centra-se em como trabalhar a igualdade na diferença: "não se trata de, para afirmar a igualdade, negar diferença. E nem de uma visão diferencialista absoluta, que relativize a igualdade". Para Sodré (2006, pp. 10-11), a diversidade humana:

[...] é algo a ser mais sentido do que entendido. Vamos traduzir isto para um modo de entendimento mais simples. Um indivíduo mora em São Paulo e está habituado ao uso de técnicas modernas no cotidiano, está informado dos acontecimentos do mundo pela televisão, é cristão, sabe ler e escrever, etc. Um outro indivíduo mora no Parque do Xingu (em Mato Grosso) e, mesmo que a gente saiba 
que a tecnologia já chegou até ele, vamos imaginar que aquele espaço, com suas circunstâncias (a floresta, a tradição tribal, a aparência física das pessoas, as crenças religiosas, etc.), enseje uma diferença. A pura e simples comparação não nos diz nada de essencial sobre um e outro. Mas é assim que o senso comum opera: fazendo comparações. E quando o termo comparante sobrevaloriza a si mesmo por se julgar o detentor de uma verdade absoluta, 0 termo comparado é automaticamente rebaixado e discriminado.

As observações realizadas na escola de forma geral e também na sala de aula reforçam que o desafio de trabalhar a diversidade cultural para a mobilização das potencialidades não é tarefa fácil. Há muitos desafios em que se pensar, como o currículo escolar, no qual a temática dos migrantes e refugiados deveria ser um eixo narrativo, a interdisciplinaridade e de que forma se pode trabalhar com esses alunos de forma a mobilizar suas forças para o sucesso do processo de ensino e aprendizagem.

\section{Notas sobre o currículo escolar}

Quanto à questão do currículo como princípio norteador da escola, cita-se Moreira, A. F. B. (2009, p. 5), que o define como o "verdadeiro coração da escola". Pressupõe-se, assim, a necessidade de permanentes discussões que permitam avanços na compreensão do processo escolar e suas relações com a sociedade, a cultura, o momento histórico no qual se vive.

O currículo é considerado um artefato social e cultural. Isso significa que ele é colocado na moldura mais ampla de suas determinações sociais, de sua história, de sua produção contextual. O currículo não é um elemento inocente e neutro de transmissão desinteressada do conhecimento social. O currículo está implicado em relações de poder, o currículo transmite visões sociais particulares e interessadas, - currículo produz identidades individuais e sociais particulares (MOREIRA; SILVA, 1994, p. 7).

Importante destacar que o currículo escolar esteve, durante muito tempo, enraizado através da cultura ocidental e em quase sua totalidade, na cultura europeia. Conteúdos de história que valorizam museus, líderes políticos e movimentos colonizadores fizeram e fazem parte do currículo escolar. Em contrapartida, percebem-se, ainda que lentamente, mudanças através de reformas educacionais baseadas em movimentos de lutas sociais. 
Cita-se aqui, a questão da obrigatoriedade do ensino da cultura afro e indígena no currículo de história, levando a crer que esta modificação permitirá a abertura para uma educação que valorize também a cultura oriental e suas tradições, não a tratando de forma marginalizada, quando retrata a cultura islâmica através do extremismo religioso, grupos terroristas que não condizem com o seu legado. Considerando as implicações entre o currículo e a cultura, recorre-se novamente à Moreira e Silva (1994, pp. 2627):

Em contraste com o pensamento convencional, sobre a relação entre currículo e cultura, a tradição crítica vê o currículo como terreno de produção e criação simbólica, cultural. A educação e o currículo não atuam, nessa visão, apenas como correias transmissoras de uma cultura produzida em um outro local, por outros agentes, mas são partes integrantes e ativas de um processo de produção e criação de sentidos, de significações, de sujeitos. O currículo pode ser movimentado por intenções oficiais de transmissão de uma cultura oficial, mas o resultado nunca será o intencionado porque, precisamente, essa transmissão se dá em um contexto cultural de significação ativa dos materiais recebidos. A cultura e o cultural nesse sentido, não estão tanto naquilo que se transmite quanto naquilo que se faz com o que se transmite.

Além da temática do currículo que permeia os desafios de trabalhar a diversidade cultural na educação, pode-se lançar ainda, reflexões acerca da interdisciplinaridade, que, de acordo com Gallo (2000), significa a necessidade de um inter-relacionamento entre todas as disciplinas. Para ele:

\begin{abstract}
Quando assiste a uma aula de História, cada aluno abre a "gavetinha" de seu "arquivo mental" em que guarda os conhecimentos históricos; ao final da aula, fecha essa "gavetinha" e abre aquela referente à matéria a ser estudada na próxima aula, e assim por diante... E como cada uma das "gavetinhas" é estanque, sem nenhuma relação com as demais, os alunos não conseguem perceber que todos os conhecimentos vivenciados na escola são perspectivas diferentes de uma mesma e única realidade, parecendo cada um deles autônomo e autossuficiente, quando na verdade só pode ser compreendido em sua totalidade como parte de um conjunto, peça ímpar de um imenso puzzle que pacientemente montamos ao longo dos séculos e dos milênios (GALLO, 2000, p. 23, grifos do autor).
\end{abstract}

As práticas pedagógicas devem levar em conta a diversidade cultural e ir além da inclusão de novos conteúdos, repensando as relações étnicas, sociais, econômicas, políticas, pedagógicas e culturais e conduzir à 
aprendizagem de valores sociais e culturais do outro, de forma dialógica e relacional e não hierárquica. Através da ênfase nas diferenças, busca-se compreender o processo de inclusão e integração do aluno refugiado no contexto escolar, tendo como propósito o alcance de uma educação que considere o universo cultural no qual o aluno está inserido e que valorize a vivência do indivíduo no processo educacional.

Portanto, o processo de aprendizagem pode ser facilitado por uma metodologia pedagógica que propicie ao aluno a compreensão da sociedade em que está inserido e de seus problemas, criando a habilidade de criticar e transcender suas experiências culturais. O que se propõe é uma reflexão sobre o currículo escolar e a problematização das questões que envolvem desde a sua construção e a organização até sua vivência nas escolas, tendo como pressuposto a diversidade da sociedade contemporânea, superando a contradição histórica entre o saber e a realidade.

\section{A inclusão e as diferenças}

Quando se fala em inclusão em educação, deve-se inquirir que qualquer aluno que esteja sem se beneficiar do processo educacional, seja por qual motivo for, fica em situação de exclusão (SANTOS, 2003). Portanto, inclusão se refere a:

[...] quaisquer lutas, nos diferentes campos sociais, contra a submissão de pessoas excluídas: tanto as que se percebem com facilidade como aquelas mais sutis. Refere-se ainda, num nível mais preventivo, a todo e qualquer esforço para se evitar que alguém em risco de ser excluído de dado contexto, por qualquer motivo que seja, acabe de fato sendo excluído (SANTOS, 2003, p. 4).

Norteando-se por esse entendimento, Booth e Ainscow (2012) e Santos (2003), trazem apontamentos para um melhor entendimento da inclusão na educação e reiteram processos de aumento da participação e redução da exclusão de todos os alunos, das culturas, dos currículos e das comunidades escolares. Envolve ainda uma abordagem mais ampla na identificação do 
risco de exclusão e na tentativa de resolver as dificuldades que surgem no contexto escolar.

Inclusão é, portanto, um processo com esforços no sentido de garantir a participação de qualquer pessoa na sociedade em que vive e na qual têm direitos e deveres. E tratando-se de educação, a inclusão pressupõe processos dinâmicos para uma participação plena do aluno e de todos os participantes do processo educacional, numa estrutura em que as práticas sejam delineadas considerando as diferentes características.

A educação inclusiva não se restringe à relação professor e aluno, mas implica em uma compreensão da inclusão como um processo que envolve toda a comunidade escolar e que seja concebido como um princípio de educação para todos e valorização das diferenças.

Deve ser, portanto, uma iniciativa compartilhada, considerando a promoção da aprendizagem e da participação, o combate à discriminação e o respeito à diversidade. Um conjunto de processos que envolve o contexto escolar como um todo em busca da inclusão.

[...] inclusão é um conjunto de processos intermináveis. Ela envolve especificar a direção da mudança. Ela é relevante a qualquer escola, não importa o quanto inclusivas ou excludentes suas culturas, políticas e práticas sejam. Ela requer que as escolas se engajem num exame crítico do que pode ser feito para aumentar a participação e a aprendizagem da diversidade dos alunos dentro da sua localidade (BOOTH; AINSCOW, 2012, p. 7).

A participação significa aprender junto com os outros e colaborar com eles em experiências compartilhadas de aprendizagem. Isto requer um engajamento ativo com a aprendizagem. Trata-se de ser reconhecido, aceito e valorizado pelo que se é (BOOTH; AINSCOW, 2012).

A análise desta interface do processo de inclusão considera que, em função de um contexto cultural diversificado, o espaço escolar deve ser um ambiente socializador que incorpore as diferentes culturas e que todos possam manifestar suas ideias, sem que haja exclusão ou discriminação a partir das explicitações de suas vivências e experiências culturais. A possibilidade de troca de culturas dentro do ambiente escolar deve 
proporcionar um ambiente que facilite ao aluno refugiado, a sua participação, integração e inclusão.

Partindo-se desta premissa, pode-se auferir que o aluno refugiado, ao deparar-se com diferenças culturais e linguísticas, pode enfrentar situações de exclusão no processo educacional. Sendo assim, com a emergência da temática dos refugiados vem a necessidade de promover a inclusão, pressupondo o respeito à sua identidade e cultura, visto que a promoção das condições de sobrevivência não garantem ao refugiado espaços inclusivos, devendo haver por parte da sociedade, a compreensão da condição de refugiado e da necessidade que este possui de ter o respeito daqueles com quem passará a conviver.

Neste cenário contemporâneo, permeado por mobilidades, migrações, hibridismos, a experiência transcultural é proposta como uma forma de ampliação de todas as culturas, valorizando a cultura do outro sem abrir mão das culturas peculiares e locais.

Para André (2016), os processos migratórios trazem diversidade cultural, embora esta nem sempre seja valorizada ou mesmo percebida pelas sociedades que recebem os estrangeiros. $\bigcirc$ "ser estrangeiro" está permeado por preconceitos, indiferenças, o que acaba trazendo 0 isolamento, também no ambiente escolar. A educação deve ser baseada na aprendizagem, não apenas de conteúdos, mas na aprendizagem no sentido de convivência e respeito à nova cultura trazida pelos alunos refugiados.

Portanto, a escola deve ser um espaço de acolhimento, de solidariedade, de garantia dos direitos e, em especial, do respeito as diferenças. O processo inclusivo deve ser planejado na escola, buscando proporcionar um ambiente acolhedor para o aluno refugiado. Uma educação que se preocupe com a integração cultural e que não exclua o aluno estrangeiro se faz necessária e pesquisas recentes têm trazido algumas reflexões buscando questionar os pressupostos escolares em vista de um currículo favorável a todos os alunos.

A abordagem da perspectiva da diferença e diversidade deve ser considerada na educação, impetrando a necessidade de se pensar o 
espaço educativo como um espaço de convivência e de aprendizado com a diversidade. Esse espaço educativo está inserido numa sociedade plural e diversa, onde preconceitos e discriminações precisam ser superados.

Sodré $(2006$, p. 6), faz uma distinção entre a diversidade e a diferença, referindo a primeira como "um universal concreto de toda realização humana" e a segunda como "um universal abstrato" e defende a ideia de que os homens não são iguais, nem desiguais, mas singulares, coexistindo em sua diversidade.

O senso comum está habituado a pensar a diferença como um ponto de partida, e então julga a partir da "identidade da diferença" do outro, como se a identidade fosse alguma coisa pronta e acabada (SODRÉ, 2006, p.8, grifos do autor).

Sodré (2006, p. 9), afirma que a discriminação vem do fato de "ignorarmos afetivamente, intelectualmente que estamos excluindo o outro, o diverso, por não termos possibilidade de lidar existencialmente com a diferenciação". Afirma ainda que "aquilo que nós experimentamos de uma cultura [...] é a diversidade de seus repertórios, onde se mostram hábitos, enunciados e simbolizações" (SODRÉ, 2006, p. 11).

O respeito inclusivo envolve valorizar o outro, reconhecendo as suas contribuições através da sua individualidade e como membro do grupo. A diversidade inclui diferenças e similaridades percebidas e não percebidas entre as pessoas. "Contudo, seu uso algumas vezes é corrompido assim, e a diversidade fica então associada com alteridade; os diferentes de nós" (BOOTH; AINSCOW, 2012, p. 23).

\begin{abstract}
Uma resposta inclusiva à diversidade acolhe a criação de diversos grupos e respeita o igual valor de outros, não obstante as diferenças neles percebidas. Tal interpretação de diversidade faz dela um rico recurso para a vida e a aprendizagem, não um problema a superar. Esta resposta contrasta com uma resposta seletiva que tenta manter a uniformidade pela classificação e divisão das pessoas e as distribui em grupos dispostos segundo uma hierarquia de valor (BOOTH; AINSCOW, 2012, p. 23).
\end{abstract}

O papel trabalhoso e necessário de incluir para ensinar cabe à escola e é proporcionado pela troca de ensinamentos acerca de cultura, idioma e 
hábitos entre os alunos brasileiros e os alunos refugiados. O processo de ensino e aprendizagem deve acontecer de forma inclusiva, devendo embasar-se na criação de projetos e políticas para garantir que os alunos aprendam a língua e possam se adaptar e se integrar no contexto educacional, apesar das dificuldades de comunicação e diferenças culturais que intrincam a adaptação em uma nova realidade.

\section{As leis e as políticas públicas educacionais}

As políticas públicas para o alcance da real integração do refugiado precisam incluir projetos educacionais de conscientização da população brasileira, a fim de que esteja preparada para acolher o refugiado e as suas diferenças, possibilitando ao mesmo, o exercício pleno dos direitos a partir da sua integração em nossa sociedade.

Para Bastos (2017, p. 4):

As políticas públicas são ações desenvolvidas pelo Estado com o envolvimento de compromissos e ações que possibilitem o desenvolvimento cultural e social de um povo. É um conjunto de ações sociais que dependem, não só do governo, mas de toda a sociedade e das instituições educacionais, com intenções à garantia dos direitos à cidadania de todos, principalmente dos que escontranse no declive da pobreza. No entanto, é preciso que haja uma relação harmônica entre Estado, as entidades formadoras e a população, além da definição de algumas atividades avaliativas do planejamento dessas políticas, para a posterior busca de novas ações.

Políticas públicas voltadas à assistência e integração dos refugiados são imprescindíveis para assegurar os direitos econômicos, sociais e culturais, em especial o direito ao trabalho, à saúde e à educação. E tomando-se como referência a questão das políticas públicas, tanto a criação como a implementação, as possíveis violações de direitos humanos, a possibilidade de integração social e a garantia de promoção e proteção destes direitos no país que acolhe o refugiado, fez-se uma análise das leis educacionais para compreender o processo de inclusão do aluno refugiado no âmbito escolar. 
Neste viés educacional, percebe-se que os migrantes têm o mesmo direito à educação que as pessoas nascidas no Brasil e que este é um dos poucos direitos assegurados no sistema educacional brasileiro. A igualdade de direito de acesso à educação para estrangeiros e brasileiros é determinada na Lei de Diretrizes e Bases da Educação (LDB). Ainda, as leis referentes às migrações garantem que a falta de documentos não pode impedir o acesso à matrícula nas escolas.

De acordo com a lei no 9.394 de 20 de dezembro de 1996, que estabelece as Diretrizes e Bases da Educação, LDB, o ensino deverá ser baseado em alguns princípios, citando entre outros: igualdade de condições para o acesso e permanência na escola; liberdade de aprender, ensinar, pesquisar e divulgar a cultura, o pensamento, a arte e o saber; pluralismo de ideias e de concepções pedagógicas; respeito à liberdade e apreço à tolerância; valorização da experiência extraescolar; vinculação entre a educação escolar, o trabalho e as práticas sociais; consideração com a diversidade étnico-racial (BRASIL, 1996).

Moreira, L. A. L. (2008), relata que a partir da criação da Lei de Diretrizes e Bases da Educação, em 1996, iniciaram-se reformas na estrutura educacional brasileira, proporcionando a elaboração de outros documentos, como os Parâmetros Curriculares Nacionais, as Diretrizes Curriculares Nacionais, entre outros. Isto demonstrou que a formação do educador e do educando estavam em processo de reestruturação.

Porém, para Saviani (1998), estas reformas educativas remetem à valorização dos mecanismos de mercado, reduzem custos e investimentos, restringem as responsabilidades do Estado.

[...] em todas as iniciativas de política educacional, apesar de seu caráter localizado e de aparência de autonomia e desarticulação entre elas, encontramos um ponto comum que atravessa todas elas: o empenho em reduzir custos, encargos e investimentos públicos buscando senão transferi-los, ao menos dividi-los (parceria é a palavra da moda) com a iniciativa privada e as organizações não governamentais (SAVIANI, 1998, p. 201). 
Além da Lei de Diretrizes e Bases da Educação, foram elaborados os Parâmetros Curriculares Nacionais, que de acordo com Candau (2008, p.18), "suscitaram grandes controvérsias quanto à sua concepção, processo de construção e estruturação interna, incorporou entre os temas transversais o da pluralidade cultural".

\begin{abstract}
A abordagem defendida pelos Parâmetros Curriculares Nacionais apresenta a sociabilidade do capital como algo insuperável e intocável, cabendo apenas transformar a consciência dos homens, capacitando-os para o enfrentamento dos desafios de um mundo tecnologicamente desenvolvido e economicamente mundializado. A crítica realizada por nossa análise, pauta-se na explicitação das implicações e limites dessa proposta para a formação humana, compreendendo que a proposta dos documentos analisados mantém os efeitos do trabalho alienado sobre o trabalhador, legitimando e naturalizando a desumanização inerente às relações sociais da sociabilidade capitalista. Quanto à vida coletiva, os Parâmetros Curriculares Nacionais e os Temas Transversais sugerem a cidadania e o mercado consumidor. Entendemos que essa vida coletiva tem uma existência abstrata e vazia de sentido, pois restringe-se ao espaço da política e do mercado, controlados e necessários à reprodução desse sistema (MOREIRA, L. A. L., 2008, p. 31).
\end{abstract}

O documento traz a introdução da temática da pluralidade cultural no currículo escolar e tem como objetivo conhecer e valorizar a pluralidade cultural brasileira e de outros povos, tendo um posicionamento contrário à qualquer discriminação baseada em diferenças culturais, crenças, etnias e explicita que, como docentes, é preciso agir para que as diferenças agreguem valores e conhecimentos e que novas culturas sejam disseminadas, fazendo com que todos os alunos se sintam e sejam pertencentes à sociedade. Para que isso ocorra não poderá haver discriminação e inferiorização de culturas distintas, mas que estas diferenças também sejam valorizadas e exploradas. O mesmo documento ainda se refere ao fato de que os conhecimentos e experiências trocadas com a diversidade são enriquecedoras para a construção da própria identidade, uma vez que nenhuma cultura pode ser definida como propriamente genuína, sem a influência de outras culturas (BRASIL, 1997).

O professor deve estar atento para que utilize a diversidade e pluralidade como ferramenta do saber e não apoie atitudes de repúdio ao 
diferente. O docente deve ter consciência do seu papel de mediador e traçar planos para que as diferenças sejam bem aproveitadas dentro do contexto escolar. Torna-se necessário, no processo educativo, possibilitar a troca de conhecimentos no âmbito cultural, propiciando um ambiente facilitador da aprendizagem, sendo possível fazer a disseminação do respeito mútuo e a aprendizagem em relação à descoberta e exploração de novas culturas.

A educação tem por objetivo a formação de cidadãos e não apenas alunos aprendizes do saber científico, confirmando a importância da diversidade cultural no âmbito escolar.

A criança na escola convive com a diversidade e poderá aprender com ela. Singularidades presentes nas características de cultura, de etnias, de regiões, de famílias, são de fato percebidas com mais clareza quando colocadas junto a outras. A percepção de cada um, individualmente, elabora-se com maior precisão graças ao Outro, que se coloca como limite e possibilidade. Limite, de quem efetivamente cada um é. Possibilidade, de vínculos, realizações de "vir-a-ser". Para tanto, há necessidade de a escola instrumentalizar-se para fornecer informações mais precisas a questões que vêm sendo indevidamente respondidas pelo senso comum, quando não ignoradas por um silencioso constrangimento. Esta proposta traz a necessidade imperiosa da formação de professores no tema da Pluralidade Cultural (BRASIL, 1997, p. 24, grifos do autor).

Para Canen (2000), neste documento a diversidade cultural está limitada à fatos históricos, ritos e costumes referentes à grupos destacados, na medida em que é tratada em um tom narrativo. Pode-se observar que docentes e discentes parecem não estar incluídos na problemática, muito embora se percebam tentativas de reconhecimento da pluralidade identitária de grupos socioculturais e a busca de superação da homogeneização cultural. Para Canen (2000, p. 144), percebe-se, no desenvolvimento dos temas propostos, "um engessamento de pluralidade de identidades culturais em termos de uma homogeneização de grupos culturais específicos".

Tratando-se desta homogeneização de grupos culturais, Canen (2000, p. 144, grifos do autor), cita o processo de migração e a pluralidade de etnias e salienta que, ainda que os povos que emigram para o Brasil sejam 
decritos, "O tratamento ao tema rompe com a perspectiva multicultural dinâmica e recai na descrição de formas de vida desses grupos, tomados como categorias homogêneas".

Uma crítica trazida por Chaddad (2015, p. 5), reside no fato de que os Parâmetros Curriculares Nacionais não buscam "a emancipação do ser humano, apenas seu adestramento ao sistema de produção capitalista". Infere-se que estes documentos não contemplam um processo democrático em sua construção, e sim, sua elaboração "encerra em si a instrumentalização do processo - a razão instrumental, em detrimento de uma construção crítica e emancipatória" (CHADDAD, 2015, p. 12).

[...] ao invés de buscar a emancipação do ser humano, busca com todas as suas forças atrelar o homem a este sistema produtivo tão desigual e alienante. Neste caso, o caminho deveria ser inverso, ou seja, libertá-lo das amarras deste sistema explorador do homem e da natureza que se move, sobretudo, pela razão instrumental - a técnica sem ética e ou sabedoria (CHADDAD, 2015, p. 18).

Canen (2000, p. 145), denuncia um viés psicológico contido no discurso dos parâmetros, quando o preconceito e a necessidade de combatê-lo são mencionados. Este tom psicológico evita uma análise que localize "a origem das discriminações que calam as vozes de grupos socioculturais diversos em práticas pedagógicas que privilegiam padrões culturais dominantes".

[...] ainda que, no nível discursivo, os parâmetros consigam dar conta da perspectiva intercultural crítica [...], fica claro que tal perspectiva não se sustenta, quando se analisa 0 documento mais detalhadamente. De fato, a perspectiva intercultural crítica dilui-se e esvazia-se em um discurso em que predomina uma perspectiva de educação multicultural para a aceitação, uma visão de pluralidade cultural que ignora a dinamicidade e a hibridização de culturas e uma não-problematização da identidade nacional, [...]. Entretanto, [...] o fato de que a pluralidade cultural passa a ser reconhecida no âmbito da proposta curricular em foco pode ser interpretado como um avanço significativo na área. Nessa perspectiva, cabe aceitar o desafio de visualizar as contradições detectadas no discurso dos PCNs (Brasil, 1997) como pontos de partida para uma perspectiva de trabalho que supere o congelamento de uma identidade nacional, que busque a compreensão da dinamicidade e do hibridismo culturais e que lance um olhar crítico e desafiador a preconceitos e estereótipos, em busca de uma valorização da cidadania plural e concreta nas práticas curriculares (CANEN, 2000, p. 146-147). 
Recentemente, os Parâmetros Nacionais Curriculares foram reforçados com a criação da Base Nacional Comum Curricular (BNCC), a qual define as competências que expressam os direitos de aprendizagem dos estudantes, incluindo, entre outros, a valorização da diversidade de saberes e vivências culturais e o exercício da empatia, do diálogo, da resolução de conflitos de forma harmônica, fazendo-se respeitar, bem como promover o respeito ao outro e aos direitos humanos, com acolhimento e valorização da diversidade de indivíduos e de grupos sociais, seus saberes, identidades, culturas e potencialidades, sem preconceitos de qualquer natureza (BRASIL, 2017).

Vale acrescentar que, tendo como referência a BNCC, os currículos da Educação Básica devem incluir temas transversais que tratem de questões contemporâneas relevantes para o desenvolvimento da cidadania em escala local, regional e global. Assim, no artigo $8^{\circ}$ :

Os currículos, coerentes com a proposta pedagógica da instituição ou rede de ensino, devem adequar as proposições da BNCC à sua realidade, considerando, para tanto, o contexto e as características dos estudantes, devendo: [...] Selecionar e aplicar metodologias e estratégias didático-pedagógicas diversificadas, recorrendo a ritmos diferenciados e a conteúdos complementares, se necessário, para trabalhar com as necessidades de diferentes grupos de alunos, suas famílias e cultura de origem, suas comunidades, seus grupos de socialização, entre outros fatores [...] (BRASIL, 2017, p. 52).

O mesmo parecer ainda traz como pressupostos a compreensão de si e do outro como identidades diferentes, de maneira que se exercite o respeito à diferença, em uma sociedade plural, além de promover os direitos humanos e a interpretação e expressão dos sentimentos, crenças e dúvidas com relação a si mesmo, aos outros e às diferentes culturas promovendo, com isso, o acolhimento e a valorização da diversidade (BRASIL, 2017).

Em se tratando de documentos em nível estadual, encontra-se a Proposta Curricular de Santa Catarina, atualizada em 2014 e que trata da diversidade como princípio formativo, buscando a compreensão de que a valorização da diferença não se dá apenas pela aceitação e tolerância, mas pelo respeito e pelo reconhecimento. 
A proposta relata a necessidade de combater as formas de discriminação ainda existentes, combinando pactos nacionais e internacionais de proteção aos direitos humanos com medidas e políticas que acelerem a construção de uma cultura de direitos em que se reconheçam as diferentes identidades, como processo de inclusão de grupos socialmente vulneráveis (SANTA CATARINA, 2014).

De acordo com Tomelin (2016), esta proposta curricular que norteia cada fazer da escola pública catarinente expressa o caráter ideológico proposto para a rede pública do Estado de Santa Catarina, já que, para a definição de estratégias e materialização de escolhas, a ideologia se torna indispensável. Mediante o desejo da proposta em apontar um currículo, há a necessidade de estabelecer os propósitos que este currículo deverá atender.

A proposta pontua que, ao considerar as diferenças entre os alunos, a revisão e a reorganização curricular tornam-se necessárias, uma vez que devam considerar o sujeito como cidadão pleno e integral e que tem o direito de frequentar uma escola voltada para a diversidade, oportunizando convivências e vivências reflexivas em espaços culturais plurais (SANTA CATARINA, 2014).

Tomelin (2016), afirma que, em um contexto de universalidade de direitos e oportunidades, há que se considerar uma educação com a capacidade de produzir sujeitos únicos, associando igualdade e diversidade e que ocultar esses aspectos não significa um ensino sem ideologias, mas sim, um ensino baseado na exclusão.

Seguindo-se este argumento, refere-se que as contradições e desafios apontados, ao mesmo tempo em que demonstram ser profícua uma maior clareza no esclarecimento das intenções e dos objetivos para o trabalho com a educação multicultural, asseveram que o fato de o tema ser incorporado nos documentos curriculares pode representar um ponto de partida para que as práticas pedagógicas sejam repensadas, levando em conta a pluralidade cultural. Para Canen (2000, p. 147-148, grifos do autor): 
"pluralidade cultural" indica a diversidade de significados de que se revestem tais expressões e a relevância em se proceder à sua desconstrução e reconstrução, em uma perspectiva transformadora e crítica, em cursos de formação inicial e continuada de docentes, de forma que propostas curriculares concretizem-se em práticas educativas cotidianas, viabilizadoras da formação de cidadãos críticos e participantes em sociedades cada vez mais multiculturais.

Dessa forma, com a presença de refugiados no Brasil, como alunos na rede de ensino e mediante a inexistência de leis específicas recorrentes a esta temática, percebe-se a necessidade de uma maior observação no sentido de promover a integração social e evitar a exclusão. Suas especificidades não devem ser elemento para a construção de desigualdades, discriminações ou exclusões, mas sim, devem ser norteadoras de políticas afirmativas de respeito à diversidade, voltadas para a construção de contextos sociais inclusivos.

\section{CONCLUSÃO}

A análise dos documentos jurídicos pertinentes à temática educacional permitiu concluir que o acesso à educação está garantido. Os refugiados têm o mesmo direito à educação que as pessoas nascidas no Brasil, contudo, este é um dos poucos direitos assegurados no sistema educacional brasileiro.

Quanto à temática da pluralidade cultural no currículo escolar, conclui-se que está definida nos Parâmetros Curriculares Nacionais e em nível estadual, na Proposta Curricular de Santa Catarina. Esta última, seguindo o mesmo viés dos Parâmetros Curriculares Nacionais, pontua que, ao considerar as diferenças entre os alunos, a revisão e a reorganização curricular tornam-se necessárias, uma vez que devam considerar o sujeito como cidadão pleno e integral e que tem o direito de frequentar uma escola voltada para a diversidade, oportunizando convivências e vivências reflexivas em espaços culturais plurais. Os Parâmetros Curriculares Nacionais tem como objetivo conhecer e valorizar a pluralidade cultural brasileira e de outros povos, tendo um posicionamento contrário à qualquer discriminação baseada em diferenças culturais, crenças, etnias. Porém, Canen (2000), 
destaca uma crítica à narrativa deste documento que limita a diversidade cultural à fatos históricos, ritos e costumes referentes à grupos destacados. Assim como Hall (2003), quando cita a celebração dos turbantes africanos e colares indígenas. Isto demonstra documentos educacionais calcados mais na questão de estudar o diferente (ritos, costumes, tradições) do que em uma questão de incluir/incorporar estas diferenças no cotidiano, fazendo com que o ensino continue baseado em uma cultura hegemônica. E citando Barzotto (2004), que postula uma linha de pensamento em que as propostas pedagógicas não deveriam estar centradas nos verbos respeitar, valorizar, adequar e sim, incorporar. Respeitar, valorizar e adequar as diferenças culturais, pressupõe hierarquia, julgamentos de valor, o que pode ser traduzido em formas discriminatórias e exclusivas.

Sendo assim, a partir da análise das leis que regem a educação, assevera-se que, muito embora elas garantam o respeito à diversidade e prezam pela inclusão no ambiente escolar, não especificam a questão do aluno estrangeiro, refugiado ou migrante não oferecendo nenhum tipo de apoio ao acolhimento deste, como aprendizagem da língua portuguesa ou acompanhamento psicológico, tendendo muito mais a excluir do que incluir do contexto escolar.

Contudo, embora não tratem diretamente da questão dos estrangeiros, o fato de o tema da diversidade cultural ser incorporado nos documentos curriculares pode representar um ponto de partida para que as práticas pedagógicas sejam repensadas, levando em conta a pluralidade cultural. As dinâmicas para o favorecimento e a efetivação da inclusão de alunos estrangeiros devem se basear na incorporação de novas culturas, novas características.

A partir desta análise e reflexão, percebeu-se que uma postura educacional voltada para a inclusão dos alunos refugiados será o principal mecanismo para desencadear mudanças no processo educacional vigente, no sentido da promoção do respeito e incorporação da diversidade. Mediante tais mudanças será possível uma maior reflexão sobre quais saberes estão sendo adotados e como estes irão interferir na construção de 
um novo saber pedagógico, voltado para a inclusão de valores sociais, morais e religiosos, partindo da escola e por consequência, o meio social, trazendo a inclusão de diferentes etnias, culturas. Partindo-se desse pressuposto e tendo como alicerce leis que regulamentam os direitos humanos, sinaliza-se a necessidade de garantir o acesso e participação de todos, indiferentemente de suas raízes culturais.

\section{REFERÊNCIAS}

ANDRÉ, B. P. A diversidade dos alunos estrangeiros e seu processo de adaptação em escolas brasileiras. In: BAHIA, J.; SANTOS, M. Um olhar sobre as diferenças: a interface entre projetos educativos e migratórios. São Leopoldo: Oikos, 2016. p. 56-78. Disponível em:

<http://oikoseditora.com.br/files/Um\%20olhar\%20sobre\%20as\%20diferen\%C3\% A7as\%20-\%20e-book\%20-\%20BAHIA\%20e\%20SANTOS.pdf> Acesso em: $10 \mathrm{fev}$. 2019.

BARZOTTO, V. H. Nem respeitar, nem valorizar, nem adequar as variedade linguísticas. Revista Ecos. Edição nº 002 - Julho 2004. Disponível em: <https://periodicos.unemat.br/index.php/ecos/article/view/1049/1136> Acesso em: 10 jan. 2019.

BASTOS, M. de J. Políticas Públicas na Educação Brasileira. Revista Científica Multidisciplinar Núcleo do Conhecimento. Edição 05. Ano 02, Vol. 01. pp. 253263, Julho de 2017.

BHABHA, H. O Local da Cultura. Belo Horizonte: UFMG, 1998.

BOOTH, T.; AINSCOW, M. Index Para a Inclusão. Desenvolvendo a aprendizagem e a participação nas escolas. Traduzido por: Mônica Pereira dos Santos e João Batista Esteves. LaPEADE: 2012.

BRASIL, Lei de Diretrizes e Bases da Educação Nacional (1996). Disponível em: <http://www.planalto.gov.br/ccivil_03/leis/L9394.htm.> Acesso em: 14 dez. 2018.

BRASIL. Parâmetros curriculares nacionais: pluralidade cultural, orientação sexual. Brasília: MEC/SEF, 1997, 164p. Disponível em:

<http://portal.mec.gov.br/seb/arquivos/pdf/livro101.pdf> Acesso em: 25 nov. 2018.

CANDAU, V. M. Multiculturalismo e educação: desafios para a prática pedagógica. In: MOREIRA, A. F.; CANDAU, V. M. Multiculturalismo: diferenças culturais e práticas pedagógicas. 2. ed., Petrópolis, RJ: Vozes, 2008. 
CANEN, A. Educação multicultural, identidade nacional e pluralidade cultural: tensões e implicações curriculares. Revista Cadernos de pesquisa. $N^{\circ}$ 111, São Paulo: 2000.

CHADDAD, F. R. Análise Crítica da Elaboração, da Pedagogia e da Orientação dos PCNS. Revista Mimesis. Bauru, v. 36, n. 1, 2015.

EAGLETON, T. A ideia de cultura. São Paulo: Ed. Unesp, 2005.

GALLO, S. Transversalidade e educação: pensando uma educação nãodisciplinar. In: ALVES, N.; GARCIA, R. L. O Sentido da Escola. Rio de Janeiro: DP\&A, 2000.

HALL, S. Da diáspora: identidades e mediações culturais. Organização Liv Sovik; Tradução Adelaine La Guardia Resende et al. Belo Horizonte: Editora UFMG, 2003.

HALL, S. A identidade cultural na Pós-modernidade. Tradução: Tomaz Tadeu da Silva e Guacira Lopes Louro. $11^{\mathrm{a}}$ ed. DP\&A Editora, Rio de Janeiro: 2006.

LANKSHEAR, C.; KNOBEL, M. Pesquisa pedagógica: do projeto a Implementação. Porto Alegre: Artmed. 2008.

MOREIRA, A. F. B. Currículo: conhecimento e cultura. In: Salto para o futuro. Brasil: Ministério da Educação, Secretaria da Educação à Distância, 2009. p. 4-9. Disponível em:

<http://portaldoprofessor.mec.gov.br/storage/materiais/0000012193.pdf> Acesso em: 06 jan. 2019.

MOREIRA, A. F. B.; CANDAU, V. M. Educação escolar e cultura(s): construindo caminhos. Revista Brasileira de Educação. $N^{\circ} 23,2003$. Disponível em: <http://www.scielo.br/pdf/rbedu/n23/n23al1 > Acesso em: 16 dez. 2018.

MOREIRA, A. F. B.; SILVA, T. T. da. Sociologia e teoria crítica do currículo: uma introdução. In: MOREIRA, A. F. B.; SILVA, T. T. da. Currículo, cultura e sociedade. São Paulo: Cortez,1994. p. 7-31.

MOREIRA, L. A. L. Os parâmetros curriculares nacionais (PCN) e a educação brasileira sob a supremacia do mercado. Revista Cidadania \& Movimentos Sociais. Campinas, v.9, n.2, p.31-51, jun. 2008. Disponível em: <https://periodicos.sbu.unicamp.br/ojs/index.php/etd/article/view/815> Acesso em: 10 dez. 2018.

MOREIRA, J. B. Refugiados no Brasil: reflexões acerca do processo de integração local. REMHU - Rev. Interdisciplinar de Mobilidade Humana, Brasília, Ano XXII, n. 43, p. 85-98, jul./dez. 2014. Disponível em: 
<http://www.scielo.br/pdf/remhu/v22n43/v22n43a06.pdf> Acesso em: 22 nov. 2018.

SANTOS, M. P. dos. O papel do ensino superior na proposta de uma educação inclusiva. Revista Movimento, Faculdade de Educação da UFF, no. 7, Maio de 2003. p. 78-91.

SANTA CATARINA. Secretaria de Estado da Educação. Proposta Curricular de Santa Catarina: formação integral na educação básica. 2014. Disponível em: <http://www.propostacurricular.sed.sc.gov.br/site/Proposta_Curricular_final.p df> Acesso em: 20 dez. 2018.

SAVIANI, D. A nova lei da educação: trajetória, limites e perspectivas. $4^{a}$ edição. Campinas, SP: Autores Associados, 1998.

SEVERINO, A. J. A educação e a construção do sentido da humanidade. In: Atas V COLÓQUIO INTERNACIONAL SOFELP, 2016. p. 211 - 216. Disponível em: <https://www.researchgate.net/publication/322210487> Acesso em: 10 mai. 2018.

SODRÉ, M. Diversidade e diferença. Revista Científica de Información y Comunicación. Número 3, Sevilla: 2006. Disponível em: <http://institucional.us.es/revistas/comunicacion/3/artl.pdf> Acesso em: 30 jan. 2019.

TOMELIN, N. B. O Caráter Ideológico da Educação Básica e a Proposta Curricular de Santa Catarina. Revista Gestão Universitária, 2016. Disponível em: <http://www.gestaouniversitaria.com.br/artigos/o-carater-ideologicoda-educacao-basica-e-a-proposta-curricular-de-santa-catarina> Acesso em: 06 dez. 2018.

Recebido em: 28 de fevereiro de 2019 Aprovado em: 03 de julho de 2019 